\title{
Do Quanta Need a New Logic?
}

\author{
John Stachel* \\ Center for Einstein Studies, Boston University \\ E-mail: john.stachelegmail.com
}

\begin{abstract}
What is Logic? My answer consists of three steps: Logic is about Language, Language is about the World. Panlogism is the attempt to "short circuit" this process by identifying the real object and the "concrete-in- thought." It leads to the assertion: Logic is about the World. If we abandon panlogism, we see that quantum logics (note the plural!) are just different ways of reformulating the same content. The danger: is that, If we accept the idea of one unique quantum logic, that provides all the answers, this prevents us from confronting the real questions about quantum mechanics.
\end{abstract}

Frontiers of Fundamental Physics 14 - FFP14,

15-18 July 2014

Aix Marseille University (AMU) Saint-Charles Campus, Marseille

${ }^{*}$ Speaker. 